\title{
An overgrowth disorder associated with excessive production of cGMP due to a gain-of-function mutation of the natriuretic peptide receptor 2 (NPR2) gene
}

\author{
Kohji Miura ${ }^{1 *}$, Noriyuki Namba', Keiko Yamamoto', Makoto Fujiwara', Yasuhisa Ohata', Taichi Kitaoka', \\ Takuo Kubota', Toshimi Michigami², Keiichi Ozono'
}

From 7th APPES Biennial Scientific Meeting

Nusa Dua, Bali. 14-17 November 2012

\begin{abstract}
Aim
In human, overproduction of C-type natriuretic peptide (CNP) due to a chromosomal translocation was reported to cause skeletal dysplasia associated with tall stature. In addition, acromesomelic dysplasia, type Maroteaux, characterized by dwarfism is caused by loss-of-function mutations in the Npr2 genethat encodes the CNP receptor NPR2.We report a three-generation family with tall stature, scoliosis and macrodactyly of the great toes, leading to a gain-of-function mutation in Npr2.
\end{abstract}

\section{Methods and results}

Since the phenotype of the patients resembled several cases of the CNP overproduction phenotype, in terms of tall stature and large great toes, enhanced CNP/NPR2 signaling was suspected. Since the proband's phenotype showed similarity to CATSHL syndrome, caused by a loss-of-function mutation in the Fgfr3 gene, except for the absence of neurological symptoms, the Fgfr3 gene was analyzed as well as the natriuretic peptide precursor $\mathrm{C}(\mathrm{Nppc}), \mathrm{Npr} 2$, and Npr3 genesand a novel heterozygous $\mathrm{G} \rightarrow \mathrm{A}$ missense mutation at nucleotide +2647 (c.2647G $\rightarrow$ A) of the Npr2 gene was identified.When expressed in HEK293A cells, the mutant Npr2cDNA generated intracellular cGMP in the absence of CNP ligand. In the presence of CNP, cGMP production was greater in cells that had been transfected with the mutant Npr2cDNA compared to wild-type cDNA. Transgenic mice in which the mutant $N p r 2$ was expressed in chondrocytes driven by the promoter and intronic enhancer of the Col11a2 gene exhibited an enhanced production of cGMP in cartilage, leading to a similar phenotype to that observed in the patients.

\section{Conclusion}

These results indicate that p.Val883Met is a constitutive active gain-of-function mutation and elevated levels of cGMP in growth plates lead to the elongation of long bones.Our findings reveal a critical role for NPR2 in skeletal growth in both humans and mice, and may provide a potential target for prevention and treatment of diseases caused by impaired production of cGMP, such as pulmonary hypertension, short stature, erectile dysfunction, heart failure, placental dysfunction, and dementia.

\section{Authors' details}

'Departments of Pediatrics, Osaka University Graduate School of Medicine, Japan. ${ }^{2}$ Department of Bone and Mineral Research, Osaka Medical Center and Research Institute for Maternal and Child Health, Japan.

Published: 3 October 2013

\section{doi:10.1186/1687-9856-2013-S1-O43}

Cite this article as: Miura et al:: An overgrowth disorder associated with excessive production of CGMP due to a gain-of-function mutation of the natriuretic peptide receptor 2 (NPR2) gene. International Journal of Pediatric Endocrinology 2013 2013(Suppl 1):O43. 